\title{
16
}

\section{SWMM 5 - the Next Generation of EPA's Storm Water Management Model}

\author{
Lewis A. Rossman, Robert Dickinson, Trent Schade, Carl Chan, \\ Edward $H$. Burgess, Daniel Sullivan, Fu-Hsiung Lai
}

The U.S. Environmental Protection Agency's Water Supply and Water Resources Division is partnering with the consulting firm of CDM to redevelop and modernize the Storm Water Management Model (SWMM). The initial phase of this project is rewriting SWMM's computational engine using an object-based approach, providing the program with a rudimentary graphical user interface, and producing complete documentation of the program and its code. Future work will focus on improving key computational components within SWMM and enhancing SWMM's ability to model BMP and LID alternatives. The latest version of the updated SWMM can be downloaded from www.epa.gov/ ednnrmrl/swmm.

\subsection{Introduction}

SWMM (Huber and Dickinson, 1988) is a dynamic rainfall-runoff simulation model, used for single-event or long-term (continuous) simulation of runoff quantity and quality from primarily urban areas. It is one of the most successful models produced by the U.S. Environmental Protection Agency (EPA) for the water environment. Originally developed in 1969-71, it has withstood the test of time and continues to be widely used worldwide for analysis of quantity and quality problems related to stormwater runoff, combined sewers, sanitary sewers, and other drainage systems in urban areas, with many applications in non-urban areas as well.

Rossman, L.A., R.E. Dickinson, T. Schade, C.C. Chan, E. Burgess, D. Sullivan and F. Lai. 2004. "SWMM 5 - the Next Generation of EPA's Storm Water Management Model." Journal of Water Management Modeling R220-16. doi: 10.14796/JWMM.R220-16.

(C) CHI 2004 www.chijournal.org ISSN: 2292-6062 (Formerly in Innovative Modeling of Urban Water Systems. ISBN: 0-9683681-9-0) 
SWMM is considered by many in the engineering community in the U.S. to be the de facto "model" for comprehensive hydrologic/hydraulic/water quality analyses associated with urban sewer systems. It has enjoyed a highly useful life of over $30 \mathrm{y}$. As a consequence, the interest in, and desire for, a better SWMM have not faded with time. Instead, the needs and wishes of the SWMM user community increases as computer technology improves and the public's expectations of a cleaner environment rise. This chapter describes the progress made to date on EPA's efforts to modernize and redevelop the SWMM software package.

\subsection{Objectives}

The goal of EPA's SWMM Redevelopment Project is to help meet the needs of EPA's clients for improved computational tools for managing urban runoff and wet weather water quality problems. The project seeks to produce a new version of SWMM that incorporates modern software engineering methods as well as updated computational techniques. The specific objectives of the project are:

- to revise the architecture of the SWMM computational engine, using object-based programming techniques, to make it easier for the model to be maintained, upgraded, and interfaced with other software,

- to provide a rudimentary graphical user interface (GUI) to the engine to improve the usability of the model,

- to remove obsolete features, improve key computational aspects, and add new computational capabilities to the model where warranted,

- to develop guidelines on how SWMM can be used to model more recently developed Best Management Practices (BMPs) and Low Impact Development (LID) for runoff control in urban areas.

The end products from this project will consist of the following:

- a newly coded version of the SWMM computational engine, to be known as SWMM 5, that can be run either as a stand-alone application or as a library of functions that can be called from other applications such as third party vendors of SWMM,

- a GUI shell program that will run under Windows, access the SWMM 5 engine through library calls, and include a contextsensitive, on-line Help system, and 
- full documentation in the form of a Users Manual, a Programmer's Manual, and a Reference Manual.

\subsection{Rationale}

The SWMM Redevelopment Project is being undertaken for the following reasons:

- The current SWMM 4.4 code consists of more than 50,000 lines of FORTRAN that have been patched together over some $30 \mathrm{y}$ with a very uneven level of commenting and documentation. There is just a handful of people in the world who can confidently make revisions to the code without fearing that major bugs will be introduced in the process. The code needs to be restructured, preferably in an object oriented manner. The restructured code will be more manageable, understandable, and maintainable. It will sustain SWMM's accessibility to a new generation of modelers.

- Over its development it appears that new features were only added to SWMM but obsolete ones were never removed. Examples of the latter include the Graph module, the use of Dust and Dirt as a measure of runoff quality, and the capability to read NWS rainfall data in obsolete formats. The obsolete and unessential features should be identified and removed to make the code more streamlined and maintainable.

- The input file format used to describe a drainage area and control a simulation using SWMM is antiquated and unwieldy. The requirements it imposes on users to specify how the various modules in SWMM should be linked together through scratch files are the source of frequent input errors. The numerous "card codes" used to identify blocks of related data are non-intuitive and require constant references be made to the Users Manual. There is no facility to interactively view selected portions of the voluminous output produced by SWMM in a visually intuitive way. A graphical user interface is sorely needed to improve the way that SWMM can be utilized most effectively.

- The Transport and Extran blocks, which use different computational methods to route flow through the same physical set of conduits, are not data compatible with each other. Users must 
prepare two sets of very similar data if they want to run both the kinematic wave (Transport) and the dynamic wave (Extran) routing methods for the same set of conduits.

- The Extran module does not include routing of water quality constituents. This precludes the use of this powerful tool in water quality studies.

- SWMM has limited ability to simulate Real Time Control (RTC) through the remote manipulation of control structures (e.g., regulators, gates, orifices, weirs, pumps) within a sewer system, based on conditions (e.g. stage, flow rates, water quality, sediment depth) in order to optimize utilization of available insystem storage and operation. For SWMM to improve its RTC capability, the numerical stability and computational efficiency of its Extran module needs to be improved as does its user interface used to define control rules.

\subsection{Participants}

The redevelopment project is a joint effort between EPA-NRMRL's Water Supply and Water Resources Division and Camp Dresser and McKee Inc. (CDM). CDM's participation is through a CRADA (Cooperative Research and Development Agreement) between itself and the Agency. Through this agreement they donate in-kind services, share technical expertise and collaborate with EPA engineers and scientists in the following areas:

- supply technical and programming expertise on the current SWMM code,

- suggest needed revisions and updates to the code,

- update and improve the Extran (full dynamic flow routing) portion of SWMM,

- develop data file converters for previous versions of SWMM input and output, and

- help implement quality assurance testing.

In addition to CDM, the consulting services of Dr. Wayne Huber of Oregon State University, one of the original developers and a long-time maintainer of the SWMM code, have been acquired. Dr. Huber is assisting the project team in understanding the legacy FORTRAN code contained in the current SWMM program and is preparing a Reference Manual that will be part of the project's set of documentation. 
Two other groups have been invited to participate in the project. One is a Technical Design Panel made up of modeling experts who have suggested and critiqued the form, function, and technical direction that the project has taken. The second group is the current SWMM user community, as well as vendors of SWMM pre/post-processor software. This group has been kept informed of the intent and progress of the project and been asked to serve as beta testers of preliminary versions of the redeveloped SWMM 5.

\subsection{Approach}

The work envisioned for this project has been divided into nine task areas as follows:

1. re-examine SWMM's functionality,

2. re-write SWMM's computational engine,

3. adapt an existing graphical user interface for use with SWMM,

4. update and add to SWMM's computational algorithms,

5. develop a new input data file format,

6. develop converters for input from previous versions of SWMM,

7. identify how state-of-the-art BMP/LID modeling can be incorporated into SWMM,

8. prepare program documentation, and

9. conduct quality assurance testing.

\subsubsection{SWWM's Functionality}

Since this project afforded the opportunity to rebuild SWMM from the ground up, it seemed worthwhile to ask which computational features currently contained in SWMM could be eliminated, which should be retained in their current form, which are in need of updating, and which additional features should be added. Based on input received from the project's Technical Design Panel, Table 16.1 lists the computational functionality to be included in the initial re-write of SWMM. Features being dropped because they are based on obsolete data or are seldom (or incorrectly) used include:

- dry weather flow regression equations,

- support for obsolete rain file formats,

- flow routing through gutters and pipes in Runoff,

- drain infiltration calculations in Transport, 
Table 16.1 Functionality included in SWMM 5.

\begin{tabular}{ll}
\hline Rainfall Data & Cross-Sections \\
\hline User-Supplied Time Series & Simple Geometries \\
Current NWS and AES File Formats & Non-Standard Geometries \\
Event Statistics (SYNOP) & Natural Channels and Bridges \\
& Flow Routing \\
Infiltration & Uniform Flow \\
Horton & Kinematic Wave \\
Green Ampt & Dynamic Wave \\
Curve Number & Pollutant Loading \\
Groundwater & Buildup and Washoff \\
Two-Zone Model & Erosion \\
Snowmelt & Dry Weather Flow \\
Degree Day Model & Street Cleaning \\
Evaporation Data & Pollutant Routing \\
User-Supplied Monthly Averages & CSTR Model \\
NWS Meteorological Files & \\
& \\
Temperature Data & Sediment Transport \\
NWS Meteorological Files & Shields Scour/Deposition \\
Overland Flow & Storage/Treatment \\
Nonlinear Reservoir Model & Generalized Storage Unit Reactor Model \\
Drainage System Elements & Real Time Control \\
Pipes and Channels & Level Control \\
Pumps, Orifices, and Weirs & Timer Control \\
Flow Dividers & Rule-based Control \\
Storage Units & \\
\hline
\end{tabular}

- backwater elements in Transport,

- special treatment of catchbasins, and

- dust and dirt as a measure of pollutant buildup.

\subsubsection{The Computational Engine}

The computational engine which implements the modeling functionality embedded in SWMM 5 is being re-written in C using an object-based approach. Figure 16.1 provides an overview of the engine along with its interaction between external files and the GUI. The processing steps carried out by the engine unfold as follows: 


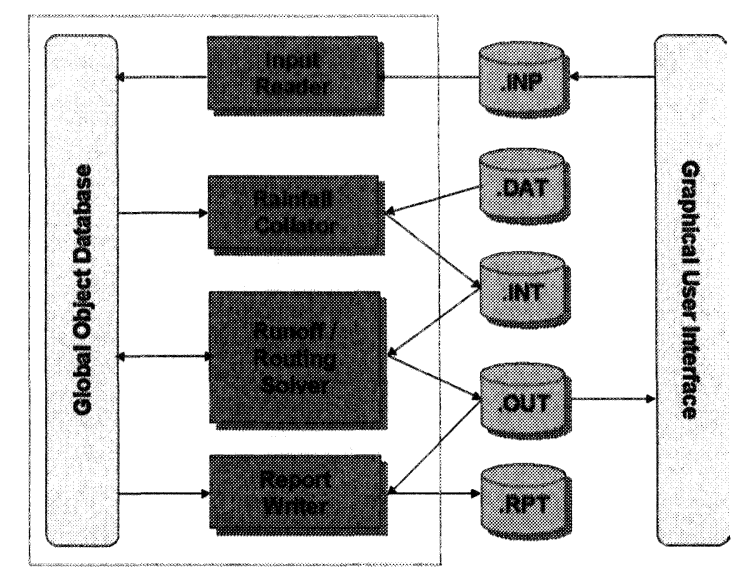

Figure 16.1 Overview of SWMM 5's computational engine.

The Input Reader receives a description of the study area being simulated from an external input text file (.INP). This file is either generated by the GUI and delivered to the engine via a function call or is supplied on the command line when SWMM 5 is run in stand-alone fashion. Its contents are parsed, interpreted, and stored in the Global Object Database.

If rainfall data comes from historical records stored in external files then a Rainfall Collator is invoked to combine the records from one or more files into a single binary rainfall interface file (.INT). This file can be saved and used again on subsequent simulations.

The Runoff/Routing Solver is then used to carry out the simulation over the stipulated period of time. Unlike prior versions of SWMM, runoff and routing steps are computed in parallel rather than sequentially. That is, whenever the routing time clock moves past the time at which runoff was last computed, a new runoff computation is made so that input can be supplied to the routing routines. Results for both runoff and routing are written to a binary output file (.OUT) at a fixed reporting time step.

If the run is being made via the stand-alone version of SWMM 5 then the Report Writer reads back the computed simulation results from the binary output file for each reporting period and writes out selected values to a formatted report file (.RPT). Any error or warning messages generated during the run are also written to this file. Otherwise, control is returned to the GUI which can access the binary output file to display results in a variety of different formats (see below). 
The internals of the engine have been coded in an object-based fashion. The code defines separate data structures for each class of object in the program. These include physical objects, such as subcatchments, storage units, conduits, pumps, etc. as well as such non-physical objects as time series, pump operating curves, and control rules. Each data structure contains a set of properties that completely describe the object. As an example, Table 16.2 contains the data structure used for a conveyance system Link. The input properties are listed first followed by the output or computed properties. The type property indicates what sub-type the link is (e.g. a conduit, pump, orifice, or weir). A separate set of data structures are defined for each of these subtypes, containing only the properties that are unique to the sub-type. The Global Object Database for a project is a collection of arrays of these data structures. That is, there is an array of subcatchment data structures, an array of link data structures, and so on.

Table 16.2 Data structure for the link class.

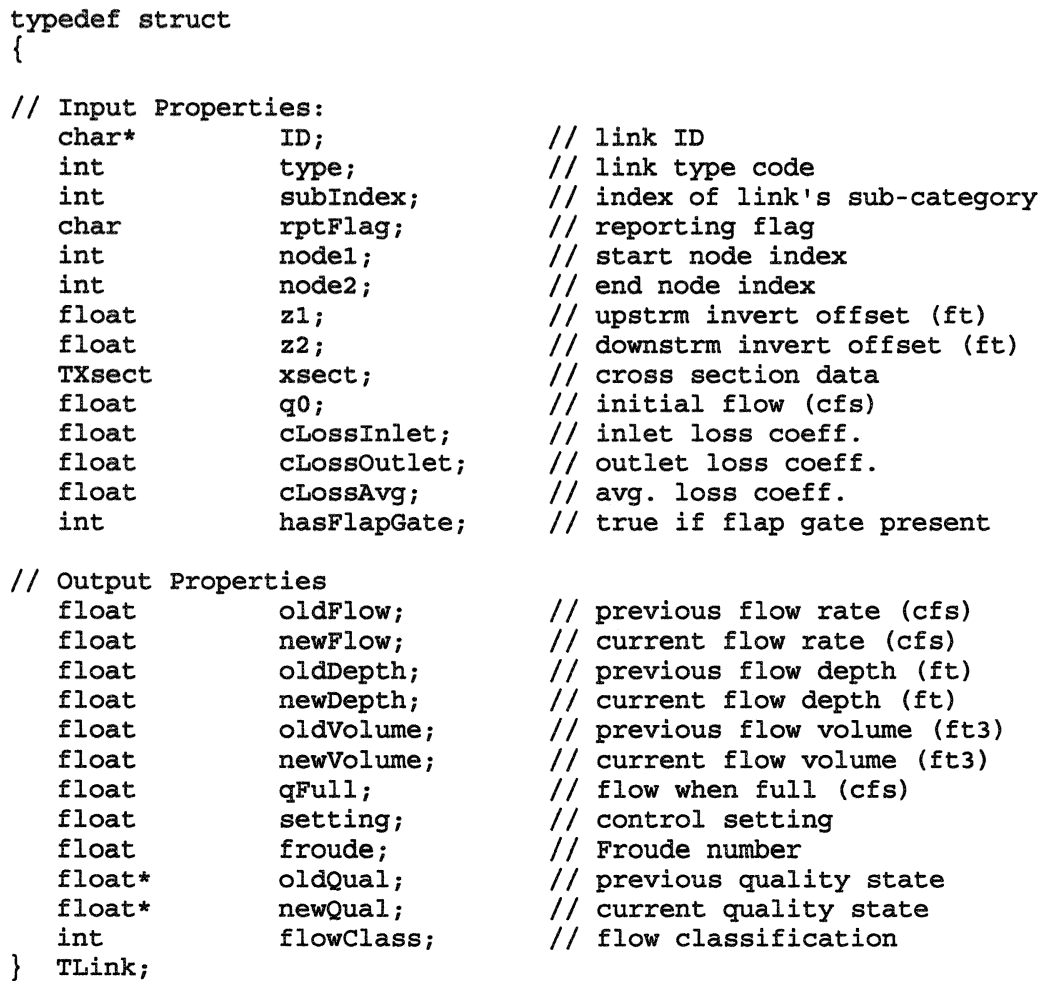


Each class of object also has its own source code module that contains all of the functions associated with the object. Functions that must be called from other modules are made global in scope and their names are prefixed with the name of the code module. All other class functions remain local to the class module. For example, the external functions associated with the Link class that appear in the Link code module are listed in Table 16.3. These conventions make the source code easier to understand and manipulate.

Table 16.3 External functions for the link class.

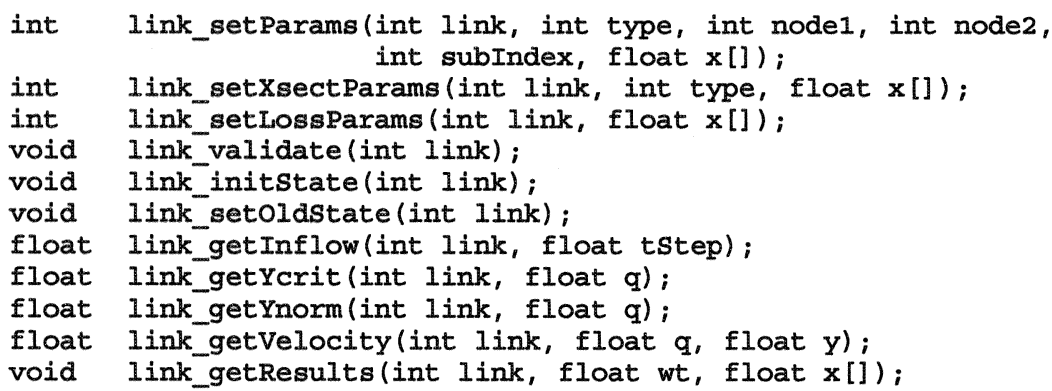

The SWMM 5 engine is delivered in two formats. One is a stand-alone executable that receives input from a text file and writes output to a text file and/ or binary output file. The other is a library of callable functions that can be accessed by other software, such as the SWMM 5 Graphical User Interface module discussed below. For the Windows operating system, the library is compiled to a DLL (Dynamic Link Library). This follows the same approach used by the highly successful EPANET model, which analyzes hydraulic and water quality behavior in drinking water distribution systems (Rossman, 2000). Only one line of code needs to be changed to compile the program as a DLL as opposed to a stand-alone executable.

\subsubsection{Graphical User Interface}

SWMM 5's new graphical user interface, shown in Figure 16.2, is being written in Object Pascal using Borland's Delphi Integrated Development Environment. It is derived from the GUI developed previously for the EPANET water distribution system software (Rossman, 2000). The panel on the left is the Data Browser, which gives the user access to the entire project database. Physical 
objects are displayed on a Study Area Map where subcatchments are represented as polygons, nodes as points, and links as polylines. New objects can be added to the map by selecting the appropriate icon from the toolbar to the left of the map and then drawing the object on the map in its proper location. Objects can be repositioned by clicking and dragging them. When nodes are re-positioned any connecting links are moved with them. After selecting a particular object on the map it's properties can be edited in the pop-up window displayed in the lower right of the figure. Special editors are available for other categories of objects that are not displayable on the map, such as pollutants, time series, and control rules.

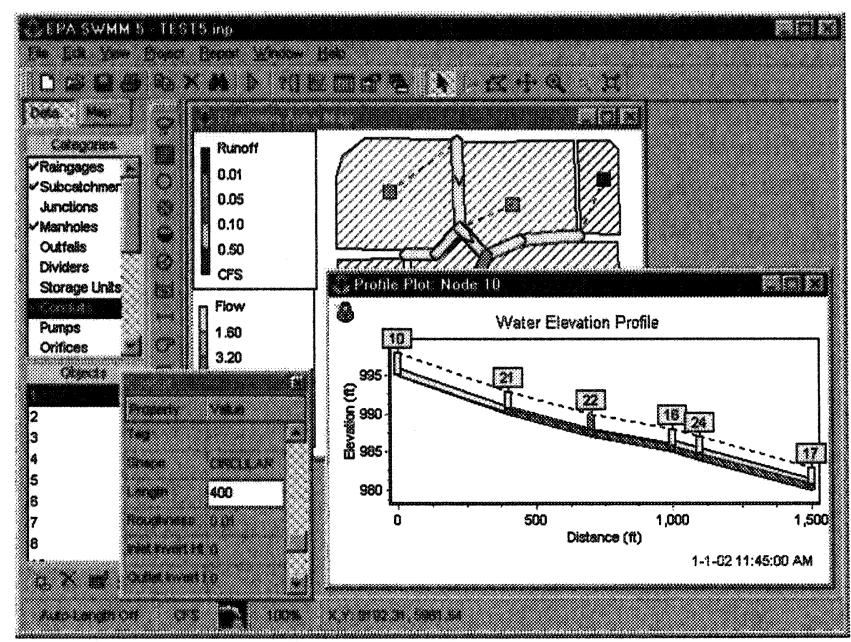

Figure 16.2 SWMM 5's Graphical User Interface.

The tab next to the Data Browser is for the Map Browser. It allows the user to select different color-coded themes to view on the map as well as move the map display forward and backward through time. Output results can also be viewed as time series plots, profile plots (as shown in Figure 16.2), scatter plots, and tabular listings. In addition, a statistical analysis of any output variable can be made that produces a frequency table of events, listing their date, magnitude, and return period, as well as a histogram of event magnitudes. The SWMM 5 GUI also contains a context-sensitive Help facility, an example of which is shown in Figure 16.3. 


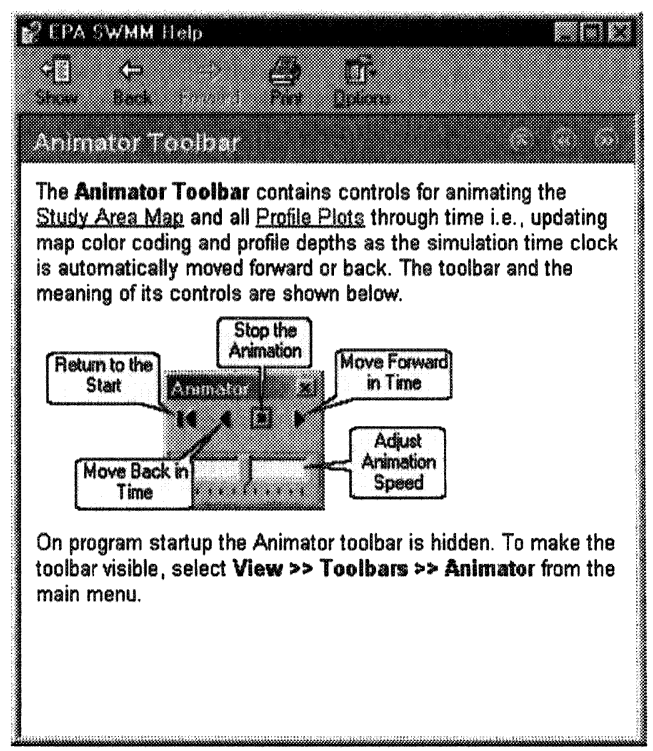

Figure 16.3 Example of SWMM 5's Help System.

\subsubsection{Computational Methods}

In this first phase of SWMM's redevelopment only modest enhancements and additions to the computational model are being made. These include the following:

Unlimited Number of Components - Unlike previous versions of SWMM no set limits are placed on the number of subcatchments, nodes, links, pollutants, land uses, etc. that can be modeled.

Curve Number Infiltration - In addition to the existing Horton and GreenAmpt models, the commonly used NRCS (SCS) Curve Number method for computing rainfall infiltration has been added (USDA, 1986). Note that this pertains to infiltration only and SWMM's nonlinear reservoir model continues to be used for runoff estimation.

Integration of Routing Methods - Previously, SWMM required that different models of the same conveyance system be created depending on whether Kinematic Wave or Dynamic Wave flow routing was being used. Now only a single description of the conveyance system is required, with the choice of routing method becoming simply an analysis option. In addition, earlier SWMM could not route water quality constituents under Dynamic Wave flow routing. This restriction has been eliminated. 
Consistent Treatment of Node Flooding - In the past, under Kinematic Wave routing, flow that exceeded the capacity of a conduit was stored at the upstream node and released into the conduit at future times when capacity became available. Under Dynamic Wave routing all flow from flooding was lost from the system. In the updated SWMM 5 the user now has a choice of which approach to use under either type of routing method.

Improved Numerical Stability for Dynamic Wave Routing - Several steps were taken to improve the numerical stability of SWMM's Dynamic Wave flow routing. These include:

- use of an inertial damping factor to reduce the influence of the inertial terms of the momentum equation as flow approaches or enters a supercritical state (Jin and Fread, 2000)

- use of a slope weighting factor to place more weight on upstream conditions as flow approaches or enters a supercritical state

- replacement of the "surcharge algorithm" of the old code with the use of a Preissmann slot to handle surcharged conditions in closed conduits (Cunge at al., 1980)

- using a Picard iteration (i.e. a successive approximation) method with under-relaxation to integrate the continuity and momentum equations over a single time step as an alternative to the modified Euler method

- computing a variable time step based on both a Courant stability criterion within conduits and a single-step limit on allowable depth changes at nodes.

More Flexible Real-Time Control Options - A rule-based syntax for specifying the on/off status of pumps, the openings of orifices and the level of weirs was added (Grayman and Rossman, 1994). It allows controls to be based on complex combinations of flows and depths at any point in the conveyance system as well as both elapsed time and time of day.

\subsubsection{Input Data File Format}

The entire input file structure of SWMM has been re-designed to make it compatible with a more integrated approach to modeling urban runoff and transport in sewers and natural channels, as well as making it easier to work with. Instead of having separate input files used for each major process, such as rainfall, runoff, and transport, input to the SWMM 5 engine is contained in a single file. Because SWMM 5 contains a Windows-based graphical user interface users normally will not have to deal directly with the input file. Instead 
Table 16.4 Example SWMM 5 input data file.

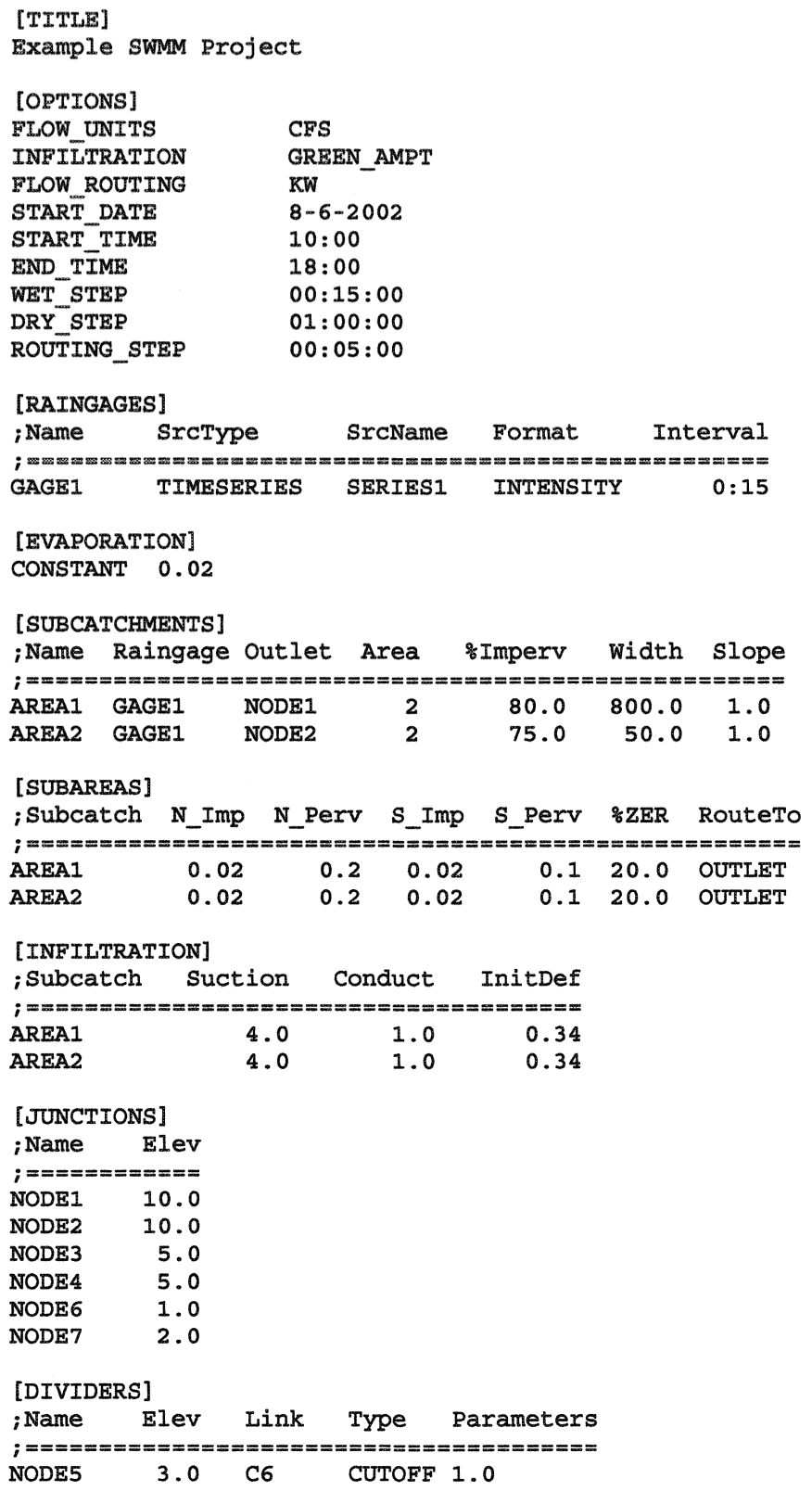


Table 16.4 Example SWMM 5 input data file (continued).

\begin{tabular}{|c|c|c|c|c|c|c|c|}
\hline \multicolumn{8}{|c|}{ [CONDUITS] } \\
\hline ;Name & Node1 & Node2 & Length & $\mathbf{N}$ & $\mathrm{Z1}$ & $\mathbf{Z 2}$ & QO \\
\hline \multicolumn{8}{|c|}{; } \\
\hline $\mathrm{Cl}$ & NODE1 & NODE3 & 800 & 0.01 & 0 & 0 & 0 \\
\hline $\mathrm{C} 2$ & NODE2 & NODE4 & 800 & 0.01 & 0 & 0 & 0 \\
\hline C3 & NODE3 & NODE5 & 400 & 0.01 & 0 & 0 & 0 \\
\hline $\mathrm{C} 4$ & NODE4 & NODE5 & 400 & 0.01 & 0 & 0 & 0 \\
\hline $\mathrm{C} 5$ & NODE5 & NODE 6 & 600 & 0.01 & 0 & 0 & 0 \\
\hline C6 & NODE5 & NODE7 & 400 & 0.01 & 0 & 0 & 0 \\
\hline
\end{tabular}

\begin{tabular}{|c|c|c|c|c|c|}
\hline \multicolumn{6}{|c|}{ [XSECTIONS] } \\
\hline ; Link & Type & G1 & G2 & G3 & G4 \\
\hline \multicolumn{6}{|c|}{; } \\
\hline $\mathrm{Cl}$ & RECT_OPEN & 0.5 & 1 & 0 & 0 \\
\hline C2 & RECT_OPEN & 0.5 & 1 & 0 & 0 \\
\hline C3 & CIRCÜLAR & 1.0 & 0 & 0 & 0 \\
\hline $\mathrm{C} 4$ & RECT_OPEN & 1.0 & 1.0 & 0 & 0 \\
\hline C5 & PARAB̄OLIC & 1.5 & 2.0 & 0 & 0 \\
\hline C6 & PARABOLIC & 1.5 & 2.0 & 0 & 0 \\
\hline
\end{tabular}

\begin{tabular}{|c|c|c|c|c|c|c|}
\hline \multicolumn{7}{|c|}{ [POLLUTANTS] } \\
\hline ; Name & Units & Cppt & Cgw & Kd & CoPollut & CoFract \\
\hline \multicolumn{7}{|c|}{ 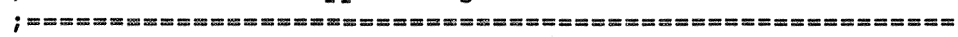 } \\
\hline TSS & mg & 0 & 0 & 0 & & \\
\hline Lead & ug & 0 & 0 & 0 & TSS & 0.20 \\
\hline
\end{tabular}

[LANDUSES]

RESIDENTIAL

UNDEVELOPED

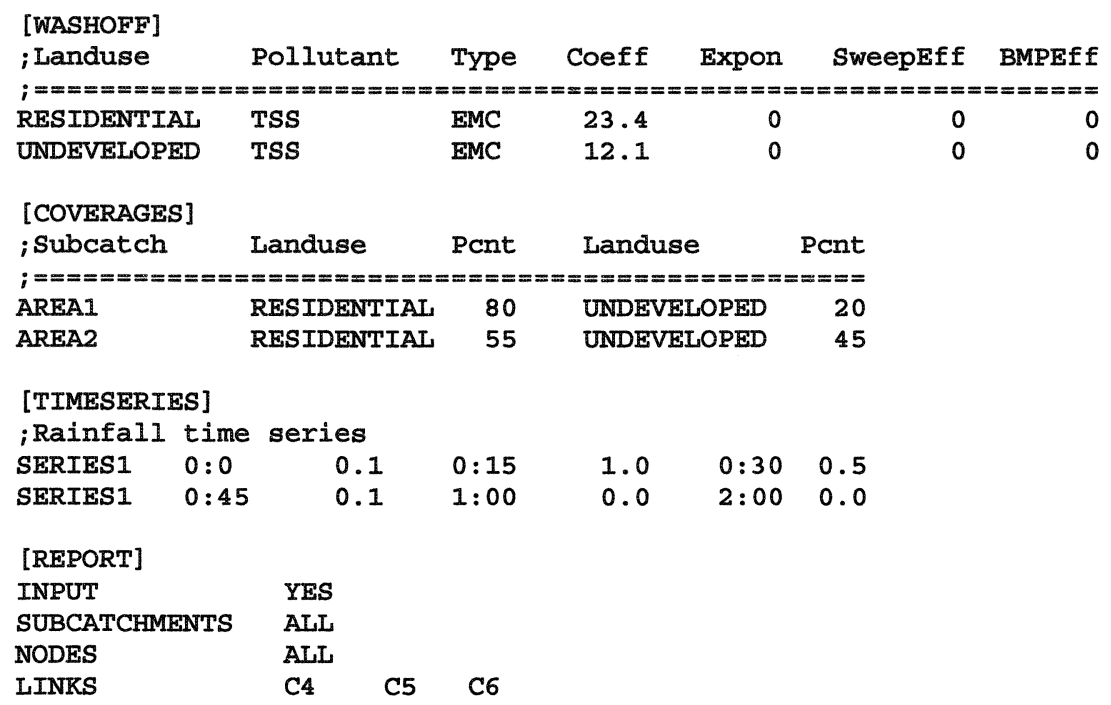


they would use the interface's input forms and graphical editors to supply the information required for their modeling project. However the SWMM 5 engine can also be run as a console application, without using the Windows interface (as with older versions of SWMM). It is also capable of being used as a library of function calls in other programs. For these kinds of applications the input file must be generated either by the user directly or by other software.

The input file is divided into several different sections. Each section begins with a specific keyword in brackets. Table 16.4 illustrates an example SWMM 5 input file. Any text appearing to the right of a semicolon is a comment added to enhance readability. The keywords and the categories of input data they represent are listed in Table 16.5 .

Table 16.5 SWMM 5 input data sections.

\begin{tabular}{|c|c|}
\hline [TITLE] & project title \\
\hline [OPTIONS] & analysis options \\
\hline [REPORT] & output reporting instructions \\
\hline [FILES] & interface file options \\
\hline [RAINGAGES] & rain gage information \\
\hline [EVAPORATION] & evaporation data \\
\hline [TEMPERATURE] & temperature data \\
\hline [SUBCATCHMENTS] & subcatchment information \\
\hline [SUBAREAS] & subcatchment impervious/pervious subarea data \\
\hline [INFILTRATION] & subcatchment infiltration parameters \\
\hline [GROUNDWATER] & subcatchment groundwater parameters \\
\hline [SNOWMELT] & subcatchment snowmelt parameters \\
\hline [JUNCTIONS] & junction node information \\
\hline [OUTFALLS] & outfall node information \\
\hline [DIVIDERS] & flow divider node information \\
\hline [STORAGE] & storage node information \\
\hline [CONDUITS] & conduit link information \\
\hline [PUMPS] & pump link information \\
\hline [ORIFICES] & orifice link information \\
\hline [WEIRS] & weir link information \\
\hline [XSECTIONS] & conduit and regulator cross-section geometry \\
\hline [TRANSECTS] & geometry for conduits with irregular cross-sections \\
\hline [LOSSES] & conduit entrance/exit losses and check valves \\
\hline [CONTROLS] & parameters that control pump \& regulator operation \\
\hline [POLLUTANTS] & pollutant information \\
\hline [LANDUSES] & land use categories \\
\hline [COVERAGES] & assignment of land uses to subcatchments \\
\hline [BUILDUP] & buildup functions for pollutants and land uses \\
\hline [WASHOFF] & washoff functions for pollutants and land uses \\
\hline [EROSION] & parameters describing soil erosion process \\
\hline [SEDIMENT] & sediment size distributions \\
\hline [TREATMENT] & ollutant removal in storage units and conduits \\
\hline [INFLOWS ] & external hydrograph/pollutograph inflow at nodes \\
\hline [DWF ] & baseline dry weather sanitary inflow at nodes \\
\hline [PATTERNS] & periodic variation in dry weather inflow \\
\hline [LOADINGS] & initial pollutant loads on subcatchments \\
\hline [TABLES] & $x-y$ tabular data referenced in other sections \\
\hline [TIMESER] & time series data referenced in other sections \\
\hline
\end{tabular}




\subsubsection{Input Data Converter}

A separate utility program is being written to convert old SWMM data sets into the format required by the updated SWMM 5. The program recognizes most of the old SWMM input line codes and creates a log file identifying which lines could not be successfully converted. One notable feature of the program is its ability to assign a consistent set of node invert elevations, which are required by the new SWMM, to old Transport data sets that contain conduit slopes rather than node elevations.

\subsubsection{BMP/LID Modeling}

SWMM already had a few processes (overland runoff, sewer routing, soil infiltration, and storage) that could be used to conceptualize BMPs and LID. However, a fresh look at the processes in SWMM is necessary so that new discovery and development in GIS technology (spatial modeling), soil infiltration, and physical, chemical, and biological processes associated with upland alternatives for stormwater management in the scale of a residential parcel can be implemented. A separate extramural research project begun in 2001 is looking into this matter. This project was designed to define the modeling concepts and mathematical formulations needed to improve SWMM for BMP/ LID assessment.

Based on the findings from this project, BMP/LID modeling guidance will be provided that describes how SWMM can be utilized and perhaps modified to accommodate the newer generation of low impact development and nonstructural BMPs that have been developed.

\subsubsection{Program Documentation}

Three manuals are being produced from the redevelopment project.

One is a Users Manual that documents the operation of the new version of SWMM. It describes the capabilities of the program, the data needed to model the various physical entities and processes in a drainage area, and mechanics involved in actually running the program. A short but fairly comprehensive tutorial problem will be included.

The second manual is a Programmer's Manual, designed to meet the needs of software developers. It provides detailed information on the structure of the code used to program the new SWMM engine and make it easier for third party 
developers to customize the new SWMM for their own specific needs. (Details of the GUI code will not be included in this manual because of its platform dependence.)

The third manual is a Reference Manual that describes the modeling philosophy of SWMM and documents the numerical models used to compute runoff, transport, storage, and treatment. This manual will also provide guidance on model setup and on selecting parameter values for various types of SWMM applications.

\subsubsection{Quality Assurance Testing}

Because of the long history associated with SWMM and the wide-spread acceptance of its numerical results, it is essential that this project contain a strong quality assurance component so that credibility and reliability of the new version be maintained. Quality assurance consists of two main activities:

- oversight, review and guidance provided by a project Technical Review Panel

- rigorous software testing conducted by the project team and outside volunteers.

A Quality Assurance Project Plan (QAPP) has been prepared (Schade, 2002). It is based on relevant agency guidance (USEPA, 1998) and discusses the planning, execution, and QA protocols that are vital to the success of the project. Elements of the plan include a needs assessment, requirements analysis, design specifications, implementation controls, testing and verification plans, and documentation requirements.

A rigorous protocol for testing the new software is being developed by the project team. It includes the compilation of input test data sets from various sources. Criteria are being developed to determine when a major discrepancy exists between numerical results obtained using the old SWMM and the new SWMM. The source of the discrepancy can then be investigated to determine if it is a legitimate difference due to a modification in a computational procedure or if it is the result of a program bug.

Another, more informal source of software testing and evaluation is being solicited through the SWMMUsers Group listserve maintained by Prof. William James at the University of Guelph. In this mode of testing, group members are asked to evaluate successive versions of the beta test program as they are released, and report back any problems they encounter to the project team. 


\subsection{Future Enhancements}

While undertaking this project several areas have been identified that could benefit from adding improved modeling methodologies to SWMM. These include the following:

- To obtain better resolution in modeling runoff quantity and quality it will be necessary to discretize subcatchment areas into component surface types rather than broad land use categories (Phillips and Thompson, 2002). Examples of such surfaces include roofs, paved areas, roads, disturbed soils, native landscapes, etc. Each surface type has a characteristic runoff/ infiltration response as well as pollutant washoff properties. This conceptualization facilitates the modeling of such BMPs as grass swales, filter strips, rain barrels, and porous pavement.

- Although the stability of the Dynamic Wave flow routing method has been improved in SWMM 5, the explicit nature of the method can still require extremely small time steps and therefore long solution times. Using an implicit scheme to solve the St. Venant equations $(\mathrm{Ji}, 1998)$ might result in greatly reduced solution times with comparable or improved stability for at least some applications.

- The accuracy of routing water quality constituents through pipes and channels could be improved by adopting one of the Lagrangian methods utilized for modeling advective transport in rivers (Jobson and Schoellhamer, 1987) and water distribution pipe networks (Rossman and Boulos, 1996).

- There is a need to model sediment buildup, washoff, transport, and removal in a more consistent manner throughout SWMM. Particle size distributions should be tracked not just through flow routing, but also during washoff from impervious surfaces and from erosion of pervious areas (Sutherland and Jelen, 2003). Sediment transport in sewers and channels should consider both the bed load and suspended load components (Delleur, 2001).

\subsection{Summary and Conclusions}

The SWMM Redevelopment Project has resulted in a complete re-coding of the SWMM engine producing a more structured and maintainable body of code. A 
single, consistent set of physical objects can now be used to model runoff from urban catchments. The numerical stability of dynamic wave flow routing has been improved and a flexible method for describing real-time control actions has been included. The program has been equipped with a graphical user interface that should allow users to become more productive speed up the learning curve for new users. The Quality Assurance program followed in this project has insured that numerical results produced from the new SWMM are comparable to those from the previous version. This redevelopment project will allow SWMM to continue to serve as a reliable public domain tool for the next generation of collection system and urban drainage modeling studies.

\section{Acknowledgments}

The material in this chapter is based on work partially funded by the U.S. Environmental Protection Agency. It has not been subject to the agency's review and, therefore, does not necessarily reflect the views of the agency, and no official endorsement should be inferred.

\section{References}

Cunge, J.A., F.M. Holly, and A. Verwey, 1980, Practical Aspects of Computational River Hydraulics, Pitman Publishing, London.

Delleur, J.W., 2001, "New Results and Research Needs on Sediment Movement in Urban Drainage", J. Water Resources Planning and Management, 127(3), 186193.

Fowler, M., 2001, “Design...Dead?”, Software Development, April.

Grayman, W.M. and L.A. Rossman, 1994, "Integrating a network model with an expert system", Computers in the Water Industry, AWWA Computer Conference, American Water Works Association, Denver, CO, 553-561.

Huber, W.C. and R.E. Dickinson, 1988, Storm Water Management Model Version 4, Users Manual, EPA/600/3-88/001a, U.S. Environmental Protection Agency, Athens, GA.

Jin, M. and D.L. Fread, 2000, "Discussion on the Application of Relaxation Scheme to Wave-Propagation Simulation in Open-Channel Networks", J. Hyd. Eng., ASCE, 126(1), 89-91.

Ji, Z., 1998, "General hydrodynamic model for sewer/channel network systems", J. Hydraulic Engineering, 124:307-315. 
Jobson, H.E. and D.H. Schoellhamer, 1987, Users manual for a branched Lagrangian transport model, US Geological Survey Water Resources Investigations 87-4163.

Mark, O. 1992, “A sediment transport model for sewers", Wat. Sci. Tech., 25:141-149.

Phillips, B.C. and G. Thompson, 2002, "Virtual Stormwater Management Planning in the 21st Century", Global Solutions for Urban Drainage, Proc. of the Ninth International Conference on Urban Drainage, E.W. Strecker and W.C. Huber, eds., American Society of Civil Engineers, Reston VA.

Rossman, L.A. and P.F. Boulos, 1996, "Numerical methods for modeling water quality in distribution systems: a comparison", J. Water Resources Planning and Management, 122:137-146.

Rossman, L.A., 2000, EPANET 2 Users Manual, EPA/600/R-00/057, National Risk Management Research Laboratory, U.S. Environmental Protection Agency, Cincinnati, $\mathrm{OH}$.

Schade, T., 2002, Quality Assurance Project Plan, SWMM Redevelopment, National Risk Management Research Laboratory, U.S. Environmental Protection Agency, Cincinnati, OH (http://www.epa.gov/ednnrmrl/swmm).

Sutherland, R. and S.L. Jelen. 2003. "Stormwater Quality Modeling Improvements Needed for SWMM." Journal of Water Management Modeling R215-13. doi: 10.14796/JWMM.R215-13.

USDA Soil Conservation Service (SCS), 1986, National Engineering Handbook, "Urban Hydrology for Small Watersheds", TR-55, U.S. Department of Agriculture, Washington, DC.

U.S. Environmental Protection Agency, 1998, EPA Guidance for Quality Assurance Project Plans (EPA QA/G-5), EPA/600/R-98/018, Office of Research and Development, Washington, D.C. 